\title{
Correction \\ Correction: Souza et al. A Regularized Mixture of Linear Experts for Quality Prediction in Multimode and Multiphase Industrial Processes. Appl. Sci. 2021, 11, 2040
}

\author{
Francisco Souza ${ }^{1,2}$, , Jérôme Mendes ${ }^{1}$ (D) and Rui Araújo ${ }^{1}$ (D) \\ 1 Department of Electrical and Computer Engineering, Institute of Systems and Robotics, \\ University of Coimbra, Pólo II, PT-3030-290 Coimbra, Portugal; jermendes@isr.uc.pt (J.M.); \\ rui@isr.uc.pt (R.A.) \\ 2 Department of Analytical Chemistry \& Chemometrics, Radboud University, \\ 6525 AJ Nijmegen, The Netherlands \\ * Correspondence: f.souza@science.ru.nl
}

check for updates

Citation: Souza, F.; Mendes, J.; Araújo, R. Correction: Souza et al. A Regularized Mixture of Linear Experts for Quality Prediction in Multimode and Multiphase Industrial Processes. Appl. Sci. 2021, 11, 2040. Appl. Sci. 2021, 11, 11581. https://doi.org/10.3390/ app112411581

Received: 13 September 2021 Accepted: 26 November 2021 Published: 7 December 2021

Publisher's Note: MDPI stays neutral with regard to jurisdictional claims in published maps and institutional affiliations.

Copyright: (c) 2021 by the authors. Licensee MDPI, Basel, Switzerland. This article is an open access article distributed under the terms and conditions of the Creative Commons Attribution (CC BY) license (https:// creativecommons.org/licenses/by/ $4.0 /)$.

\section{Text Correction}

We, the authors, wish to make the following corrections to our paper [1]. We have found that Equations (16), (21) and (22) were stated wrong in the manuscript. These equations relate to the BIC criteria for parameters and model selection.

In Equation (16), the BIC for the selection of $\lambda_{p}^{e}$ for the expert $p$ should be replaced by the correct format

$$
\operatorname{BIC}^{e}\left(\lambda_{p}^{e}, \alpha\right)=n_{p}^{e} \log \left(\sum_{i=1}^{n} \gamma_{p i}^{t}\left(y_{i}-\mathbf{x}_{i}^{T} \boldsymbol{\theta}_{p}^{t+1}\right)^{2}\right)+\log \left(n_{p}^{e}\right) \psi_{p}^{e},
$$

Similarly, in Equation (21), the BIC for the selection of $\lambda_{p}^{g}$ for the gate $p$, should be replaced by the correct format

$$
\operatorname{BIC}^{g}\left(\lambda_{p}^{g}, \alpha\right)=n_{p}^{g} \log \left(\sum_{i=1}^{n} r_{p i}\left(z_{p i}-\mathbf{x}_{i}^{T} \boldsymbol{v}_{p}^{k}\right)^{2}\right)+\log \left(n_{p}^{g}\right) \psi_{p}^{g},
$$

The BIC criteria for the model selection, stated in Equation (22) should be replaced by the correct format

$$
\operatorname{BIC}(\boldsymbol{\Omega})=m \log \left(\frac{\sum_{i=1}^{n}\left(y_{i}-\hat{y}_{i}\right)^{2}}{m}\right)+\log (m) \sum_{p=1}^{P}\left(\psi_{p}^{e}+\psi_{p}^{g}\right) .
$$

We also state that there is no impact on the experimental results, as we ran the experiments with the correct equations

The authors apologize for any inconvenience caused and state that the scientific conclusions are unaffected. The original article has been updated.

\section{Reference}

1. Souza, F.; Mendes, J.; Araújo, R. A Regularized Mixture of Linear Experts for Quality Prediction in Multimode and Multiphase Industrial Processes. Appl. Sci. 2021, 11, 2040. [CrossRef] 